\title{
Frequency and clinical patterns of stroke in Iran - Systematic and critical review
}

\author{
Akram A Hosseini ${ }^{1,4^{*}}$, Davood Sobhani-Rad ${ }^{2}$, Kavian Ghandehari ${ }^{3}$, Hani TS Benamer ${ }^{4}$
}

\begin{abstract}
Background: Cerebrovascular disease is the second commonest cause of death, and over a third of stroke deaths occur in developing countries. To fulfil the current gap on data, this systematic review is focused on the frequency of stroke, risk factors, stroke types and mortality in Iran.
\end{abstract}

Methods: Thirteen relevant articles were identified by keyword searching of PubMed, Iranmedex, Iranian University index Libraries and the official national data on burden of diseases.

Results: The publication dates ranged from 1990 to 2008. The annual stroke incidence of various ages ranged from 23 to 103 per 100,000 population. This is comparable to the figures from Arab Countries, higher than subSaharan Africa, but lower than developed countries, India, the Caribbean, Latin America, and China. Similarly to other countries, ischaemic stroke was the commonest subtype. Likewise, the most common related risk factor is hypertension in adults, but cardiac causes in young stroke. The 28-day case fatality rate is reported at 19-31\%.

Conclusions: Data on the epidemiology of stroke, its pattern and risk factors from Iran is scarce, but the available data highlights relatively low incidence of stroke. This may reflect a similarity towards the neighbouring nations, and a contrast with the West.

\section{Background}

Iran, known as Persia until 1935, is located in Southwest Asia (figure 1). With an area of 1,648,000 square kilometers, Iran ranks sixteenth in size among the countries of the world and its climate ranges from subtropical to subpolar [1]. Its has a population of 70 million, with more than 13 millions living in the capital Tehran [2]. One quarter of its people are 15 years of age or younger, compared with $7.26 \%$ of the population aged 60 or over [2]. Iran with its Indo-European origin and historically being a major crossroad for human migration is a country composed of different ethnic groups including Persian (51\%), Azeri (24\%), Gilaki and Mazandarani (8\%), Kurd (7\%), Arab (3\%) as well as, Baluch, Turkman, Jews, Armenians, Assyrians and Zoarastians [1].

Over the last couple of decades, there has been major improvement in education and health services. The number of universities has grown from 22 in 1978 to 54 state universities and 289 major private universities in

\footnotetext{
* Correspondence: ahosseini@doctors.org.uk

'Neurology Department, University Hospital Coventry and Warwickshire, Coventry, UK

Full list of author information is available at the end of the article
}

2009 [3]. The Iranian Medical Council reports over 100,000 physicians, including 660 neurologists, practising in the year 2009 [4]. However, about 150 neurologists are based in Tehran with over 40 MRI scanning centres, at least double than the necessary epuipment for the population [5]. According to the World Health Organisation (WHO), life expectancy at birth in Iran is estimated at 69 years for male and 73 years for female in 2006 [6]. The total expenditure on health in 2005 is covered by the government and the private sector at $55.8 \%$ and $44.2 \%$, respectively [6].

Cerebrovascular disease is the second commonest cause of death, and the $6^{\text {th }}$ leading cause of diseases burden globally and expected to move to the $4^{\text {th }}$ place by 2020 [7]. Over $80 \%$ of all stroke deaths in the world occur in the developing countries [8]. However, stroke is largely preventable, so knowledge of risk factors within a certain country is an essential step in reducing the stroke rate and resulting disease burden. Also, lifestyle and vascular risk factors such as hypertension and diabetes vary among different countries and cultures. An examination of stroke frequency and clinical pattern in various nations is therefore important to understand 


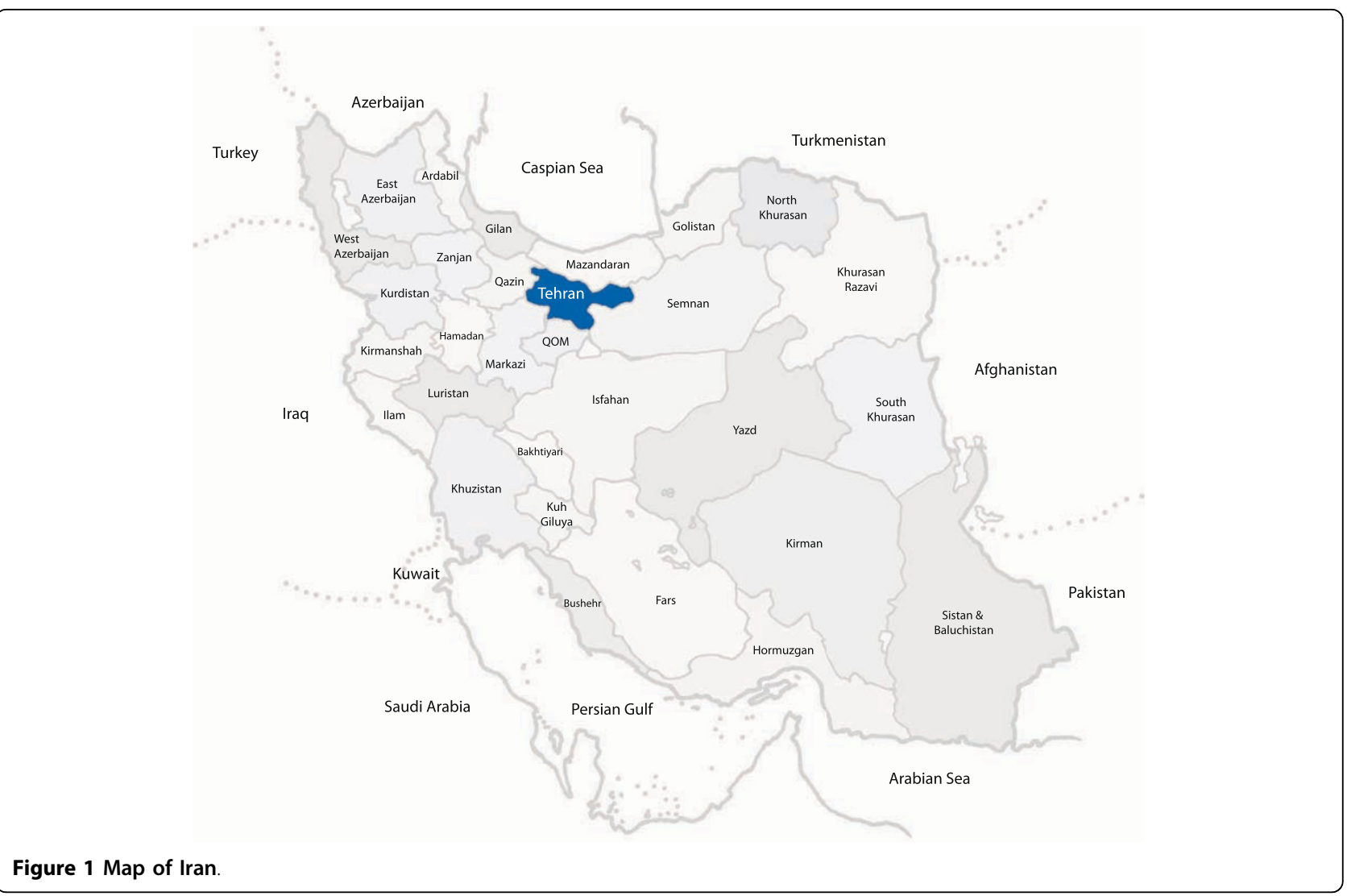

the pattern of the disease in a certain population with the ultimate aim of reducing the stroke rate. Effective prevention programmes should also be based on data relevant to the country under study. The literature representing the burden of stroke in developing countries and Asia is lacking comprehensive data on Iran. Epidemiological studies of stroke in these countries are constantly bound to numerous limitations such as inadequate nationwide data sets, lack of standard population-based studies, flawed medical registration and discontinuity of data maintenance between the family physicians, state healthcare system as well as private sector. Furthermore, those published, can remain inaccessible when written in the local or national Persian journals. The aim of this paper is to systematically review the data related to the frequency, risk factors, types and mortality of stroke in Iran. This should identify future potential research areas and help in medical service planning in the Iran. To our knowledge, no previous systematic reviews of stroke in Iran have been undertaken.

\section{Methods}

\section{Data collection}

The data was collected over four stages: -

\section{Stage 1 - search through PubMed}

Publications on Stroke in Iran were identified by searching the PubMed using the keywords:- "stroke", "intracranial bleed", "intracranial haemorrhage", "brain infarction", "cerebrovascular disorders", "cerebrovascular disease", "epidemiology", "incidence", "prevalence" combined with "Iran", "Iranian", "Persian", "Persia" and "Farsi".

Titles and abstracts were scanned by one author (AH) to identify eligible studies according to agreed inclusion and exclusion criteria. The full paper of potential studies was retrieved for more detailed assessment.

\section{Stage 2 - search through "Iranmedex" and Iranian} University Index Libraries

IranMedex is the website for Iranian medical index database (http://www.iranmedex.com). The website is a search engine to identify studies published in Persian or English, including articles in Persian or International journals, medical thesis or scientific reports. IranMedex enables one to purchase some articles or abstracts but not all.

The above mentioned keywords were used to identify articles by searching Iranmedex for further articles. The titles of all related articles and medical theses were reviewed. Since the full papers of many studies were not 
available in the website of "Iranmedex", one author (DSR) searched medical index for each major medical school in Iran, and the well-known Iranian medical journals to get hold of the relevant papers. To access the medical theses, medical index libraries were visited to copy or scan the relevant parts and forward it to the co-author $(\mathrm{AH})$.

\section{Stage 3 - search the references of the relevant papers}

Each reference in all relevant papers was checked for any additional articles.

\section{Stage 4 - Official Data on "Burden of Disease in Iran"}

The data for the year 2003 is published in a book "National Burden of Disease \& Injury in Iran", so-called "The Green Book", with exclusive rights to the Ministry of Health. It reports the results of the study on the national burden of disease. The ongoing project is implemented by the Ministry of Health and Medical Education including a team of epidemiologists, sociologists, medical and dental specialists. The study is conducted in 6 provinces including: Eastern Azarbayejan, Booshehr, Chahar Mahal \& Bakhtiari, Khorasan, Hormozgan and Yazd. A software coding system, which is comparable with global burden of disease studies, is designed for the study to collect the data from both hospitals and primary health care systems.

The access to the official data was obtained via direct communication with the current Ministry of Health in Iran. Although the data has valuable information on the nationwide burden of diseases, it does not carry strong pathophysiological and epidemiological value [9]. The reported incidence and mortality statistics are limited by inaccuracy, variable diagnostic and coding methods by both medical and non-medical administrative staff, and the absence access to detailed information on the cases, pathology subtypes, methods and individual studies. We therefore, did not include the data in this study.

\section{Inclusion and exclusion criteria}

Papers were selected for this systematic review if they fulfilled the following criteria:

1. The study was conducted in Iran,

2. The stroke is clearly defined, the definition varied in different studies: mostly defined as a focal neurological deficit, confirmed by a trained physician, that persisted for at least 24 hours; all the cases recruited to the study had brain computed tomography (CT) or magnetic resonance imaging (MRI) and underwent batteries of standard investigations including at least electrocardiography, blood count, serum electrolytes, blood sugar and lipid profile.

3. The study contained data about frequency (incidence, prevalence) or clinical pattern (types, risk factors and outcome) or mortality rate of stroke,
4. The study was published before $2^{\text {nd }}$ February 2009, and written in English or Persian,

5. Studies on cerebral venous sinus thrombosis and comparative studies on individual stroke risk factor analysis were excluded.

\section{Data extraction}

The following data were extracted from identified papers: stroke incidence, prevalence, patient sex and age, stroke type, risk factors, and clinical outcome. The included articles were reviewed and data was analysed descriptively. Statistical analysis or meta-analysis was not attempted due to significant variability in both data sources and study methodologies.

\section{Results}

The data selection process is shown in figure 2. The details of all the stroke studies in Iran, both included and excluded from this study, are tabulated in table 1. Thirteen articles, which fulfilled the inclusion and exclusion criteria, are included in this systematic review [10-22].

\section{Incidence}

There is only one study showing an incidence of 43.12/ 100,000 population/year of first-ever ischaemic stroke in all age range in Iran [17]. Whilst a study showed an annual incidence rate of 22.7 per 100,000 population for first ever and recurrent stroke, another reported a rising incidence from 84.16 to $103.23 / 100,000$ population over four years $[10,20]$. Ischaemic stroke events made up the majority in both the studies at $67 \%$ to $68 \%$ of the cases $[10,20]$. The annual incidence of young stroke (age 25$45)$ was 8 and $1.83 / 100,000$ population for children below age of $15[12,15]$. Non-traumatic brain haemorrhage was reported at 15.5 per 100,000 per year [23]. Summary of all incidence studies is shown in table 2 .

\section{Sex and Age}

Stroke was reported to be slightly more common in females (range form 51\%-53\%) in the studies that included all age range $[10,17,20]$. However, stroke was more common in young males, age between 15-45, (52\%) [15] and in boys (59\%) [12]. The clinical series showed a mean age of stroke within the $7^{\text {th }}$ decade $[10,17,20]$. However, haemorrhagic stroke was reported more commonly in women (57.9\% for intracranial haemorrhage) [21,24].

\section{Types of stroke}

Only two studies reported all types of strokes [10,20]. Ischaemic stroke was reported in $67.2-68.45 \%$ of all stroke patients while primary intracerebral haemorrhage in $23.9-28.4 \%$ and subarachnoid haemorrhage in 2.9$4.4 \%[10,20]$. One study reported that $36 \%$ of patients 


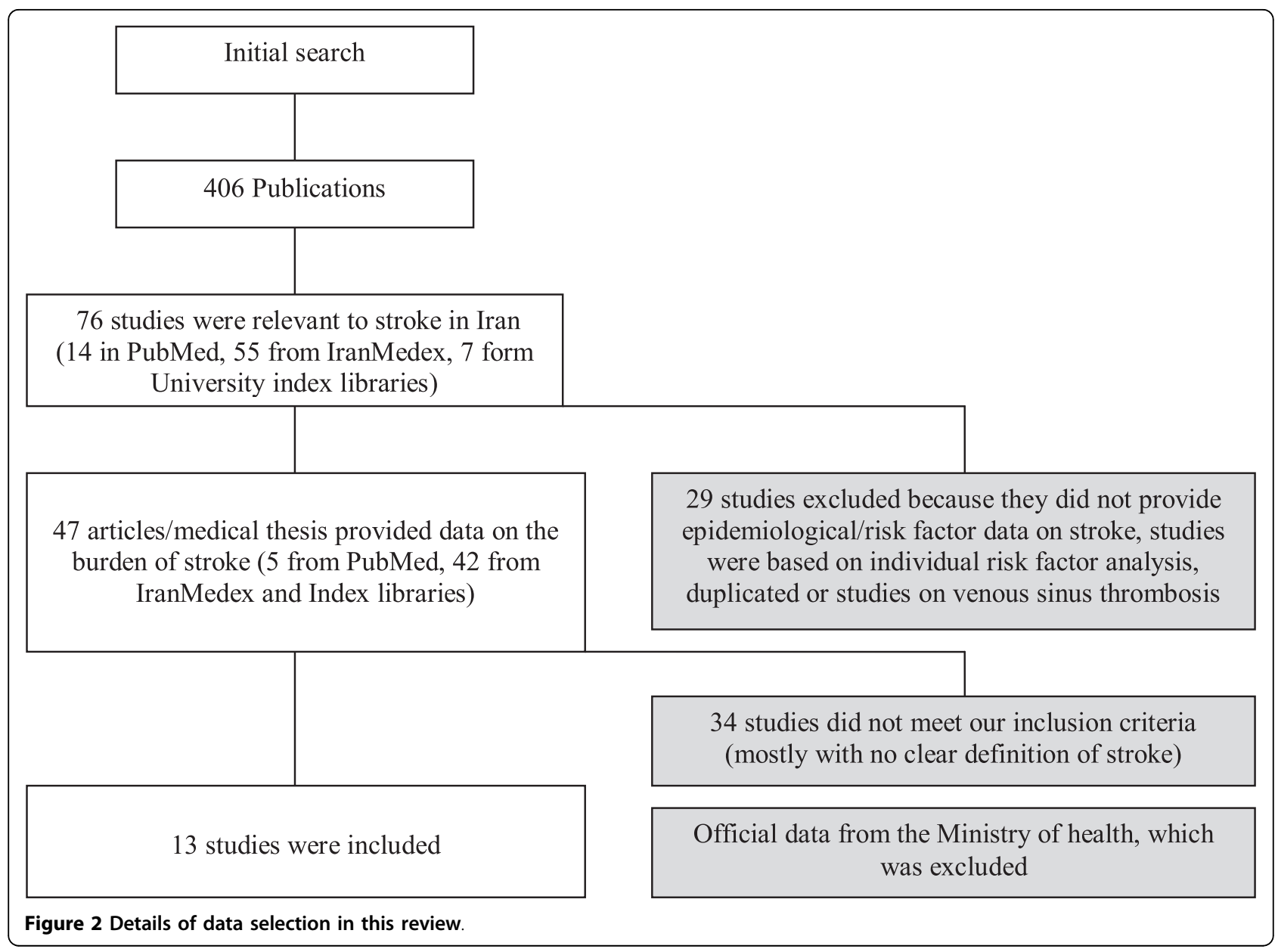

with ischaemic stroke had thrombotic event and 31.2\% had an embolic one [10]. Another study showed that $64 \%$ of patients with ischaemic stroke had a territorial infarct, $19.5 \%$ a small deep infarct and $4.6 \%$ a border zone territory infarct [17]. In this study, the distribution of stroke with atherosclerotic and cardioembolic mechanism did not show significant difference between carotid versus vertebrobasilar territory involvement [17]. One study showed that vertebro-basilar territory infarctions in $17 \%$ of women and $20 \%$ of men presented with brain infarction [17]. The only study which registered "posterior circulation strokes", reported similar gender distribution, with brain stem being the most common site of stroke (59\%) in the study group, followed by cerebellum (47\%) and mixed topographies (16\%) [13].

\section{Risk factors}

Hypertension was the most frequent risk factor in both ischaemic stroke (54\% of patients) $[10,17]$ as well as spontaneous brain haemorrhage (70\%-73.2\% of cases) [21,23]. Cardiac causes (54\%), mainly rheumatic heart disease $(34 \%)$ were the most frequent risk factor in young stroke [15]. In adults over 35 -years old, $20 \%$ of patients with ischaemic stroke had cardiac sources of embolism mainly rheumatic mitral stenosis [16]. In an aetiologic study on lacunar infarcts, hypertension, followed by diabetes and hypercholoestrolaemia were reported more frequently when compared with large vessel territory infarct. However, atrial fibrillation, ipsilateral carotid stenosis was more common in the latter; smoking and history of previous TIA were not significantly different between the two groups [11]. Summary of all risk factors of stroke in Iran are shown in table 3.

The study on the aetiologies of posterior circulation stroke, using Practical Iranian Classification [25], reported atherosclerosis being the most common cause in $50.6 \%$ of the cases, followed by uncertain causes (25.5\%), cardioembolism (12.5\%), combination of atherosclerosis and cardioembolism (6.3\%) and miscellaneous causes (4.6\%) [13].

\section{Outcome of stroke}

The case fatality rate at 28 days for all type of stroke was $19.2 \%$ in one study [10], $31.5 \%$ in another [20]. 
Table 1 Summaries of all studies on stroke in Iran

\begin{tabular}{|c|c|c|c|c|}
\hline Study & City or province & Study period in years & Published Language & Included for assessment \\
\hline Pakdaman[51] & Tehran & Four, 1986-1990 & Persian & No \\
\hline Ashrafi[52] & Urmia & Two, 1991-1992 & Persian & No \\
\hline Janghorbani, et al[53] & Kerman & Two, 1992-1994 & English & No \\
\hline Mahmoodi[54] & Yazd & $<$ two, 1993-1994 & Persian & No \\
\hline Khandaghi[55] & Tabriz & One, 1994 & Persian & $\mathrm{No}^{\mathrm{a}}$ \\
\hline Azimian, et al[56] & Hamadan & One, 1994-1995 & Persian & No \\
\hline Masoud, et al[57] & Kashan & One, 1996-1997 & Persian & No \\
\hline Ashrafi, et al[58] & Urmia & One,1997 (1 yr) & Persian & No \\
\hline Miabi, et al[59] & Tabriz & Three, 1996-1999 & Persian & No \\
\hline Ravari, et al[60] & Rafsanjan & Three, 1996-1999 & Persian & No \\
\hline Noor-Mohammadi, et al[61] & Gilan & Two, 1996-1998 & Persian & No \\
\hline Harirchian, et al[62] & Tehran & Five, 1997-2002 & English & No \\
\hline Andelib, et al[63] & Bushehr & $<$ half a year, 1998 & Persian & No \\
\hline Asadpour, et al[64] & Sanandaj & One, 1998 & Persian & No \\
\hline Masoud[65] & Tehran & < a year, 1998 & English & No \\
\hline Ebrahimi, et al[23] & Kerman & One 1998-1999 & English & No \\
\hline Razaazian, et al[66] & Kermanshah & Two,1998-2000 & Persian & No \\
\hline Hosseini, et al[67] & Gorgan & One, 1999 & Persian & No \\
\hline EmadZadeh, et al[68] & Mashhad & Three, 1999-2002 & Persian & No \\
\hline Togha, et al[22] & Tehran & Three, 1999-2002 & English & $Y_{e s}^{a}$ \\
\hline Sabet, et al[69] & Isfahan & Two, 2000-2002 & English & No \\
\hline Oveisgharan, et al[20] & Isfahan & Three, 2000-2003 & English & Yes \\
\hline Mousavi, et al[46] & Isfahan & Five, 2000-2004 & English & No \\
\hline Ghandehari, et al[70] & South. Khorasan & Five, 2000-2005 & English & Duplicate \\
\hline Ghandehari, et al[15] & South. Khorasan & Five, 2000-2005 & English & Yes \\
\hline Nikseresht, et al[19] & Shiraz & Three, 2001-2003 & Persian & Yes \\
\hline Ahangar, et al[10] & Babol & Two, 2001-2003 & English & Yes \\
\hline Ahangar, et al[71] & Babol & Two, 2001-2003 & Persian & Duplicate \\
\hline Ghandehari, et al[17] & South. Khorasan & Five, 2001-2005 & English & Yes \\
\hline Ghandehari, et al[72] & South. Khorasan & Five, 2001-2005 & English & Duplicate \\
\hline Savadi Oskoui, et al[73] & Ardabil & Half a year, 2002 & Persian & No \\
\hline Savadi Oskoui, et al[74] & Ardabil & Half a year, 2002 & Persian & No \\
\hline Noubahar, et al[75] & Semnan & One, 2002-2003 & Persian & No \\
\hline Sarsar Shahi, et al[24] & Urmia & Four, 2002-2006 & Persian & $\mathrm{No}^{\mathrm{a}}$ \\
\hline Ghandehari, et al[12] & South. Khorasan & Five, 2002-2007 & English & $Y_{e s}^{b}$ \\
\hline Parniya, et al[21] & Ardabil & One, 2003 & Persian & $\operatorname{Yes}^{\mathrm{a}}$ \\
\hline Dodangeh, et al[76] & Tehran & $<$ half a year 2003 & Persian & No \\
\hline Tavassoli, et al[77] & Tehran & Two, 2003-2005 & Persian & $\mathrm{No}^{\mathrm{b}}$ \\
\hline Amini Sani, et al[78] & Ardabil & $<$ two, 2004-2005 & Persian & $\mathrm{No}^{\mathrm{a}}$ \\
\hline Hashemilar, et al[79] & Ardabil & One, 2004-2005 & Persian & No \\
\hline Ghandehari, et al[16] & South. Khorasan & One, 2005-2006 & English & $Y_{e s}^{a}$ \\
\hline Ghandehari, et al[1 1 ] & South. Khorasan & One, 2006 & English & $Y_{e s}^{a}$ \\
\hline Ghandehari, et al[14] & South. Khorasan & One, 2006-2007 & Persian & $Y_{e s}{ }^{a}$ \\
\hline Ghandehari, et al[18] & Mashhad & One, 2007 & English & $Y_{e s}^{a}$ \\
\hline Ghandehari, et al[13] & Mashhad & Two, 2006-2007 & English & $Y_{e s}^{a}$ \\
\hline Iranmanesh, et al[80] & Rafsanjan & Not clear & English & No \\
\hline Iranmanesh, et al[81] & Rafsanjan & Not clear & Persian & No \\
\hline
\end{tabular}

${ }^{\mathrm{a} T h e}$ study does not report incidence data, but designed for risk factor, mortality or prognosis analysis. ${ }^{\mathrm{b}}$ Study on Paediatric cases. 
Table 2 Stroke demographic data in Iran

\begin{tabular}{|c|c|c|c|c|c|c|c|c|c|c|c|}
\hline Study & $\begin{array}{l}\text { City or } \\
\text { Province }\end{array}$ & $\begin{array}{l}\text { Duration } \\
\text { of } \\
\text { collection }\end{array}$ & $\begin{array}{l}\text { Sample } \\
\text { population/ } \\
\text { number of } \\
\text { events }\end{array}$ & Sex & & $\begin{array}{l}\text { Age } \\
\text { range } \\
\text { in } \\
\text { years } \\
\text { (mean } \\
\text { in } \\
\text { years) }\end{array}$ & $\begin{array}{l}\text { Diagnostic } \\
\text { criteria/CT } \\
\text { or MRI }\end{array}$ & $\begin{array}{l}\text { Case } \\
\text { ascertainment }\end{array}$ & $\begin{array}{l}\text { Study } \\
\text { design }\end{array}$ & $\begin{array}{l}\text { Event } \\
\text { type }\end{array}$ & $\begin{array}{l}\text { Total } \\
\text { population } \\
\text { per } \\
100,000 \\
(95 \% \mathrm{Cl})\end{array}$ \\
\hline & & & & Male & Female & & & & & & \\
\hline $\begin{array}{l}\text { Ahangar } \\
\text { et al[10] }\end{array}$ & Babol & $\begin{array}{l}2001- \\
2003\end{array}$ & $550,000 / 250$ & $\begin{array}{l}120 \\
(48 \%)\end{array}$ & $\begin{array}{l}130 \\
(52 \%)\end{array}$ & $\begin{array}{l}\text { All } \\
(68)\end{array}$ & WHO/all & $\begin{array}{l}\text { Hospital } \\
\text { admission (the } \\
\text { only centre for } \\
\text { stroke } \\
\text { admission in } \\
\text { the region) }\end{array}$ & Retrospective & $\begin{array}{l}\text { First-ever } \\
\& \\
\text { recurrent }\end{array}$ & 22.7 \\
\hline $\begin{array}{l}\text { Oveisgharan } \\
\text { et al[20] }\end{array}$ & Isfahan & $\begin{array}{l}2000- \\
2003\end{array}$ & $\begin{array}{l}1,700,000 / \\
4,361\end{array}$ & $\begin{array}{l}2121 \\
(49 \%)\end{array}$ & $\begin{array}{l}2240 \\
(51 \%)\end{array}$ & $\begin{array}{l}\text { All } \\
(68)\end{array}$ & WHO/90\% & $\begin{array}{l}\text { Admission in } 8 \\
\text { hospitals in } \\
\text { the region } \\
\text { (excluded } 2 \\
\text { military } \\
\text { hospitals) }\end{array}$ & Prospective & $\begin{array}{l}\text { First-ever } \\
\& \\
\text { recurrent }\end{array}$ & $\begin{array}{l}\text { a } 84.16 \\
(78.46-89.86) \\
\text { b94.84 } \\
(88.94- \\
100.74) \\
c_{100.18} \\
(94.40- \\
105.96) \\
d_{103.23} \\
(97.41- \\
109.05)\end{array}$ \\
\hline $\begin{array}{l}\text { e'Ghandehari } \\
\text { et al[17] }\end{array}$ & $\begin{array}{l}\text { Southern } \\
\text { Khorasan }\end{array}$ & $\begin{array}{l}2001- \\
2005\end{array}$ & $\begin{array}{l}682,000 / \\
1,392\end{array}$ & $\begin{array}{l}654 \\
(47 \%)\end{array}$ & $\begin{array}{l}738 \\
(53 \%)\end{array}$ & $\begin{array}{l}\text { All } \\
(65.6)\end{array}$ & ${ }^{f} \mathrm{PIC} / \mathrm{all}$ & $\begin{array}{l}\text { Hospital } \\
\text { admission (the } \\
\text { only neurology } \\
\text { centre in the } \\
\text { province) }\end{array}$ & $\begin{array}{l}\text { Prospective } \\
\text { stroke } \\
\text { registry }\end{array}$ & First-ever & 43.17 \\
\hline $\begin{array}{l}\text { e'Ghandehari } \\
\text { et al[12] }\end{array}$ & $\begin{array}{l}\text { Southern } \\
\text { Khorasan }\end{array}$ & $\begin{array}{l}2002- \\
2007\end{array}$ & $196,000 / 17$ & $\begin{array}{l}10 \\
(59 \%)\end{array}$ & $\begin{array}{l}7 \\
(41 \%)\end{array}$ & $\begin{array}{l}<15 \\
(5.5)\end{array}$ & $\begin{array}{l}{ }^{9} \text { Clinical } \\
\text { definition/ } \\
\text { all }\end{array}$ & $\begin{array}{l}\text { Hospital } \\
\text { admission (the } \\
\text { only neurology } \\
\text { centre in the } \\
\text { province) }\end{array}$ & Prospective & First-ever & 1.83 \\
\hline $\begin{array}{l}{ }^{\text {eGhandehari }} \\
\text { et al[15] }\end{array}$ & $\begin{array}{l}\text { Southern } \\
\text { Khorasan }\end{array}$ & $2000-2005$ & $314,000 / 124$ & $\begin{array}{l}64 \\
(52 \%)\end{array}$ & $\begin{array}{l}60 \\
(48 \%)\end{array}$ & $\begin{array}{l}15-45 \\
(35.7)\end{array}$ & $\begin{array}{l}{ }^{9} \text { Clinical } \\
\text { definition/ } \\
\text { all }\end{array}$ & $\begin{array}{l}\text { Hospital-based } \\
\text { study(the only } \\
\text { neurology } \\
\text { centre in the } \\
\text { province) }\end{array}$ & $\begin{array}{l}\text { stroke } \\
\text { registry }\end{array}$ & First-ever & 8 \\
\hline
\end{tabular}

CT: Computerised tomography; MRI: Magnetic Resonance Imaging; Cl: 95\% confidence intervals stated when available; WHO: World Health Organisation.

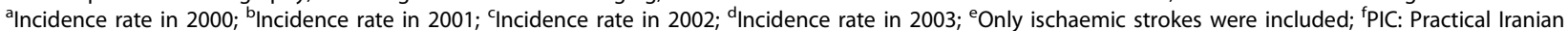
Criteria classification for aetiologic and topographic diagnosis of brain infarction; ${ }^{9}$ Stroke was defined as an ischaemic focal neurological deficit that persisted at least for 24 hours.

Table 3 Frequency of risk factors in cases of stroke admitted to hospital

\begin{tabular}{|c|c|c|c|c|c|c|c|c|c|c|c|c|}
\hline \multirow[t]{3}{*}{ Study } & \multicolumn{12}{|c|}{ Risk factors } \\
\hline & \multirow[t]{2}{*}{ Event type } & \multirow{2}{*}{$\begin{array}{l}\text { HBP } \\
(\%)\end{array}$} & \multirow{2}{*}{$\begin{array}{l}\mathrm{DM} \\
(\%)\end{array}$} & \multirow{2}{*}{$\begin{array}{l}\text { Dyslipidaemia } \\
\text { (\%) }\end{array}$} & \multicolumn{4}{|c|}{ Cardiac diseases } & \multirow{2}{*}{$\begin{array}{l}\text { Smoking } \\
(\%)\end{array}$} & \multirow{2}{*}{$\begin{array}{l}\text { CVD } \\
\text { (\%) } \\
32.8\end{array}$} & \multirow{2}{*}{$\left.\begin{array}{l}\mathrm{FH} \\
(\%)\end{array}\right)$} & \multirow{2}{*}{$\begin{array}{l}\text { tOthers } \\
(\%)\end{array}$} \\
\hline & & & & & $\begin{array}{l}\text { IHD } \\
(\%)\end{array}$ & $\begin{array}{l}\text { AF } \\
(\%)\end{array}$ & $\begin{array}{l}\text { RHD } \\
(\%)\end{array}$ & $\begin{array}{l}\text { Not } \\
\text { specified } \\
(\%)\end{array}$ & & & & \\
\hline $\begin{array}{l}\text { Ahangar, et al } \\
{[10]}\end{array}$ & Stroke & 54 & 24 & 26 & 19.2 & 16 & - & 8 & 26 & - & - & - \\
\hline $\begin{array}{l}\text { Ghandehari, } \\
\text { et al[17] }\end{array}$ & Stroke & 53.2 & 13.5 & 8 & 12.2 & 11.4 & 17.7 & 2 & 15.2 & 22.3 & 10.6 & +32.1 \\
\hline Parniya et al[21] & $\begin{array}{l}\text { Intracranial } \\
\text { Haemorrhage }\end{array}$ & 36.6 & 5.1 & 2.55 & - & - & - & 6.95 & 9.55 & - & - & - \\
\hline $\begin{array}{l}\text { Ghandehari, } \\
\text { et al[11] }\end{array}$ & Lacunar infarct & 60.4 & 20 & 23 & - & 3 & - & 23 & 14 & 15 & - & $\neq 27$ \\
\hline
\end{tabular}

HBP:Hypertension; DM: Diabetes mellitus; CVD: Previous history of cerebrovascular disease; FH: family history of stroke; IHD: Ischaemic heart disease; AF: Atrial fibrillation; RHD: Rheumatic heart disease. †Others risk factors reported include: low mobility, obesity and oral contraceptive. $¥$ ICS: Internal carotid artery stenosis 
Case fatality rate was low in ischaemic stroke (14-26\%) in comparison with haemorrhagic stroke (37.6-68\%) [10,20-22]. One study showed a mortality rate of $32 \%$ during a two year study period [10]. One hospital-based study reported $6.1 \%$ rate of vascular dementia subsequent ischaemic strokes, of those, $65 \%$ had lacunar infarct in isolation or association with large infarcts [14].

\section{Discussion}

\section{Incidence}

The available data suggest that the unadjusted incidence of stroke in Iran is comparable to the figures from Arab Countries [26-32], higher than sub-Saharan Africa [33], but lower than developed countries [34], India [35], the Caribbean \& Latin America [36], and China [37]. The apparently lower incidence may be explained by the methodological artefact, country's relative young population and hospital-based case registry in the studies. The population aged over 65 in Iran is estimated at around $5 \%$ [2], compared with $16 \%$ and $13.6 \%$ over- 65 age group in the United Kingdom and the United States of America, respectively $[38,39]$. This may have an impact on incidence reports in Iran as they are not ageadjusted. The similarities to stroke features from Arab countries might be related to ethnically heterogeneous population in Iran, consists of intermixed Persian-Arab culture, which was created since the invasion of Arabs in the $6^{\text {th }}$ century. Genetic susceptibility for stroke and risk factors are as a result of inter-marriage, co-evolution and free mixing between the individuals of both ethnic backgrounds, the impact of similar geography and environment, look-alike lifestyle and comparable relatively young population in the Arab nations may have played roles in the emergence of similar stroke pattern between Iran and Arab countries.

There has been one attempt at a community-based incidence study by running a stroke registry in the province of Southern Khorasan with over 680,000 habitants [2]. All possible stroke cases were to be referred to the Acute Stroke Unit for evaluation prior to discharge or admission. However, this has a significant impact on the data collection as it may exclude patients with mild disease or those who elect not to seek medical advice leading to under-reporting and artificially low incidence. Almost half the population seek medical advice from the private sector [6]. This figure decreases in hospital admissions but remains missing from the nationwide data particularly in the Capital Tehran with numerous private hospitals. Further studies with accepted quality criteria and age correction are essential to represent true incidence of the relatively young population of Iran.

None of the incidence studies fulfils criteria suggested by Sudlow and Warlow [40] and the updated version by Feigin [41], largely through missing a clear definition of stroke and methodological defect, in addition to lack of community-based case ascertainment, absence of age-adjusted incidence and having a retrospective design. Additionally, none of the studies was designed specifically to represent national population. Only well-designed studies with standard criteria can obtain accurate data for comparable studies on stroke, a disorder with several different pathologies and clinical presentations. Furthermore, the diverse society, heterogeneous ethnicity and marked geographical variation in the country [1] highlight the importance of conducting large studies, particularly in more populous parts in the north and the capital, to up-grade the current data to national figures. Retrospective collection of information is more liable to cause uncertainty and blurring of clinical differentiation between transient ischaemic attack and stroke; using a coding system is unreliable and vulnerable to diagnostic and administrative errors.

Since the general health care is divided between the private sector and general hospitals, the maintenance of contact, referral and follow up systems are lacking. There is no regular system of primary health care, neither is there regular contact with an organized nursing system to fulfil the sufficient criteria for adequate case ascertainment. Moreover, many patients with stroke in developing countries probably consult a private doctor before seeking hospital [42]. Repeatedly, a substantial minority presented to hospital are not admitted, highlighting the importance of the need for an expansion of case ascertainment to a comprehensive out-of-hospital case-registry system. Such a system should include general practitioners, private neurology sectors, private neuro-imaging centres and other potential sources for identifying stroke events, risk factors and outcomes. Documentation and record keeping is vital; so is more publication in internationally readable and accessible locations. By taking these measures, the current knowledge gap on stroke burden can be tackled in the country.

\section{Stroke patterns and risk factors}

Likewise in developed countries, ischaemic stroke represents the majority of stroke subtypes, followed by primary intracranial haemorrhage and subarachnoid haemorrhage $[10,20,34]$. In regards to risk factors of ischaemic stroke, high blood pressure is the commonest risk factor, as expected, followed by cardiac causes, smoking and diabetes, respectively $[10,17]$. A survey of risk factors of non-communicable diseases representing Iranian adult population showed the prevalence of hypertension and the rate of self-awareness is unacceptably high, with $25 \%$ of population aged 25-64 years being hypertensive and an additional $46 \%$ being prehypertensive [43]. The study showed that only $34 \%$ of 
hypertensive patients were aware of their elevated blood pressure and $25 \%$ were taking anti-hypertensive medications [43]. The findings place the prevalence of hypertension, obesity and overweight in Iran as high as those in the United States, with Iranian women, in contrast with men, being more obese than their American counterpartners [44]. The highly prevalent risk factors pattern is similar to the other Arab countries neighbouring the Persian Gulf [45]. Unlike developed countries, rheumatic heart disease seems to be the most common cause of cardiac sources of embolism and many from this group are not adequately managed for secondary prevention of cardio-embolic stroke [16,17]. Otherwise stroke risk factors are similar to the developing countries.

A risk factor analysis study comparing the anterior and posterior circulation strokes showed that hypertension was a major risk factor for posterior circulation stroke, followed by smoking. Hyperlipidaemia, however, was equally increased in both anterior and posterior circulation strokes [46]. Although this study was not designed for epidemiological evaluation, its investigation showed some difference in comparison with the Canadian study [47]. Diabetes mellitus (DM) was related to an increased odds of posterior circulation ischemic stroke in the latter, compared with no higher prevalence of stroke associated with DM between anterior and posterior circulation strokes in Iran $[46,47]$.

The Practical Iranian Criteria (PIC), which was designed for risk factor analysis and used for the largest epidemiological study of stroke pattern, was found reliable and useful in clinical practice [25]. It may seemingly be beneficial to standardize the criteria nationally, but lack of international recognition would limit the national studies for worldwide comparisons. Moreover, the PIC classification categorizes large artery atherosclerosis and microangiopathy as atherosclerotic mechanism, which results in an increased report of this subtype [17]. New measures and standardised risk factor analysis should also be included due to the substitution of modern life-style accompanied with higher health hazards, as well as increased global and local life-expectancy urges prevention programmes.

\section{Case fatality}

The hospital-based 28-day case fatality rate in Iran is reported at $19.2 \%$ [10] and 31.5\% [20]. The former had studied predominantly rural population near the Caspian Sea with reputation to eat seafood and have healthy diet, whereas the latter consists of over $94 \%$ urban population in the Centre of Iran. Interestingly, the incidence of stroke in the rural area at North is almost halved compared with the other urban study [20]. It may be concluded that lifestyle habits or local genetic population may explain the difference in incidence and case fatality between the two. Since there is no study designed to compare urban and rural data, the main reasons remain unclear and further studies are needed.

The case fatality of $31.5 \%$, which was reported in one study, is comparable to the figures in Sub-Saharan Africa (30\%) [33], China (27.2\% for men \& $32.9 \%$ for women) [37], Latin America \& the Caribbean (19.3 to $26.2 \%$ ) [36] and India (24.5\% for urban and $37.1 \%$ for rural population) [35]. Although the case fatality is higher than Japan (17\%), the figure is similar to the average of $22.9 \%$ reported from 13 countries from various parts of the world [34]. However, the relevance of the death registration system in Iran is highly suboptimal and the reported cause of stroke death could be up to $15 \%$ higher than the current report [48].

\section{Conclusion}

Data on the epidemiology of stroke, its pattern and risk factors from Iran is scarce. However, there are numerous case series, mostly well-designed for the local community, reported in the literature highlighting relatively low incidence of stroke. This may reflect a similarity towards the neighbouring Arab nations, and a contrast with the West. It may however, support the lack in nationwide reliable data on the epidemiology of stroke and its risk factors, frequently seen in developing countries. Without an intervention, an increase in stroke burden is expected, as a result of ageing, population growth and "health transition" $[49,50]$. To enable better healthcare planning in Iran, there is therefore, a clear necessity for well-designed population-based comprehensive studies, updated and fulfilling published quality criteria, along with public education and awareness to fighting this disabling condition in this part of the world.

\section{Acknowledgements and funding}

We acknowledge the help from Dr K. Bagheri Lankarani, Dr A.R. Mahdavi, Dr R. Najaf Abadi, Dr Olyaee Manesh and Dr Zakeri, who provided the official data on the burden of disease in Iran. The access to Persian articles would have been much harder without enormous help from Dr L.G. Tehrani, M. Yaghchi Beikloo and Dr A. Amani. The map of Iran is designed by the Medical Illustration in the Royal Wolverhampton Hospital.

\section{Author details}

${ }^{1}$ Neurology Department, University Hospital Coventry and Warwickshire, Coventry, UK. ²Paramedical Faculty, Mashhad University of Medical Sciences, Mashhad, Iran. ${ }^{3}$ Neurology Department, Mashhad University of Medical Sciences, Mashhad, Iran. ${ }^{4}$ Neurology Department, Royal Wolverhampton Hospital, Wolverhampton, UK.

\section{Authors' contributions}

$\mathrm{AH}$ designed the paper, carried out the literature search, data collection and selection (including official data from Iranian ministry of Health), analysis and interpretation of Persian and English data, and wrote the drafts. DSR participated in data collection and critical review of intellectual content. KG participated in critical review of intellectual content. HB conceived of the study, helped in the design of the paper, participated in analysis and 
interpretation of data and critical review of intellectual content. All authors read and approved the final manuscript.

\section{Competing interests}

The authors declare that they have no competing interests.

Received: 14 March 2010 Accepted: 23 August 2010

Published: 23 August 2010

\section{References}

1. Geography of Iran: facts and figures. Iran Chamber Society. 2001 [http:// www.iranchamber.com].

2. The Results of Census 2006 (1385 AD) from Statistical Centre of Iran. Statistical Centre of Iran. 2009 [http://www.sci.org.ir]

3. Higher Education in Iran. 2009 [http://www.nationmaster.com/ encyclopedia/List-of-Universities-in-Iran], NationMaster com.

4. Iranian Medical Council - Official website: Iranian Medical Council. 2009 [http://www.irimc.org].

5. Mansouri B, Ahsan B: Neurology in Iran. Iranian Journal of Neurology 2005 5(13):19-23.

6. WHO Statistical Information System (WHOSIS): Core Health Indicators database, Islamic Republic of Iran. World Health Organisation 2008.

7. Menken M, Munsat TL, Toole JF: The global burden of disease study: implications for neurology. Arch Neurol 2000, 57(3):418-420.

8. Lopez AD, Mathers CD, Ezzati M, Jamison DT, Murray CJ: Global and regional burden of disease and risk factors, 2001: systematic analysis of population health data. Lancet 2006, 367(9524):1747-1757.

9. National Burden of Disease and Injury in I.R. Iran, for the year 2003. The Ministry of Health and Medical Education, Iran. 2007.

10. Ahangar AA, shraf Vaghefi SB, Ramaezani M: Epidemiological evaluation of stroke in Babol, northern Iran (2001-2003). Eur Neurol 2005, 54(2):93-97.

11. Ghandehari K, Izadi-Mood Z: Atherosclerosis Risk Factors and Etiologic Mechanisms of Lacunar Stroke. Advanced Research Yeilds Across Atherosclerosis (ARYA) Journal 2006, 2(2):66-69.

12. Ghandehari $K$, Izadi-Mood Z: Incidence and Etiology of Pediatric Stroke in Southern Khorasan. Advanced Research Yeilds Across Atherosclerosis (ARYA) Journal 2007, 3(1):29-33.

13. Ghandehari K, Etemadi M, Nikrad M, Shakeri M, Mansoori MKhorasan: Posterior Circulation Stroke Registry: A Hospital-Based Study. Iranian Journal of Medical Sciences 2008, 33(2):67-73.

14. Ghandehari K, Riasi H: Frequency Rate of Vacular Dementia and its Relationship with Topography and Etiology in Stroke Patients. Journal of Babol University of Medical Sciences 2008, 9(6):29-33.

15. Ghandehari K, Moud ZI: Incidence and etiology of ischemic stroke in Persian young adults. Acta Neurol Scand 2006, 113(2):121-124.

16. Ghandehari K, Izadi-Mood Z: Cardiac Sources of Embolism in Iranian Stroke Patients. Arch Iran Med 2006, 2(1):7-9.

17. Ghandehari K, Izadi Z: The Khorasan Stroke Registry: results of a five-year hospital-based study. Cerebrovasc Dis 2007, 23(2-3):132-139.

18. Ghandehari K, Shuaib A, FattahZadeh Ardalani G: The frequency rate of cardioembolic etiology in North American and Iranian stroke patients: A pilot double-centre study. Iranian Red Crescent Medical Journal 2008, 10(2):66-68.

19. Nikseresht A, Jan-Azin H: Hypertension-Related Primary Cerebral Hemorrhage in Patients Referring to Hospitals Affiliated to Shiraz University of Medical Sciences. Journal of Medical Research 2003, 2(2):40-47.

20. Oveisgharan S, Sarrafzadegan N, Shirani S, Hosseini S, Hasanzadeh P, Khosravi A: Stroke in Isfahan, Iran: hospital admission and 28-day case fatality rate. Cerebrovasc Dis 2007, 24(6):495-499.

21. Parniya R, Savadi Oskoui D, Mousavi SA: Mortality Rate in Patients with Intracranial Haemorrhage and Its Risk Factors at Alavi Hospital, Ardabil. Journal of Ardabil University of Medical Sciences 2006, 6(4):363-367.

22. Togha M, Bakhtavar K: Factors associated with in-hospital mortality following intracerebral hemorrhage: a three-year study in Tehran, Iran. BMC Neurol 2004, 4:9.

23. Ebrahimi H, Shafa M, Saba M: Non-Traumatic Brain Hemorrhage in Kerman, Iran. Archives of Iranian Medicine 2000, 3(2).

24. Sarsar Shahi A, Boustani R, Sarsar Shah S, Kiani R: Evaluation of Risk Factors of Patients with Subarachnoid Hemorrhage in Motahari Hospital of
Urmia University (March 2002-March 2006). Journal of Mashhad University of Medical Sciences 2008, 50(98):367-370.

25. Ghandehari K, Mouradian M, Izadi Z, Salam A: Reliability of Practical Iranian Criteria (PIC) for Classification of Brain Infarct. Arch Iran Med 2005, 8(2):96-99.

26. Abdul-Ghaffar NU, El-Sonbaty MR, el-Din Abdul-Baky MS, Marafie AA, al-Said AM: Stroke in Kuwait: a three-year prospective study. Neuroepidemiology 1997, 16(1):40-47.

27. Al RS, Awada A, Niazi G, Larbi E: Stroke in a Saudi Arabian National Guard community. Analysis of 500 consecutive cases from a population-based hospital. Stroke 1993, 24(11):1635-1639.

28. Al-Rajeh S, Larbi EB, Bademosi O, Awada A, Yousef A, al-Freihi H, Miniawi $\mathrm{H}$ : Stroke register: experience from the eastern province of Saudi Arabia. Cerebrovasc Dis 1998, 8(2):86-89.

29. Hamad A, okrab TE, Momeni S, Mesraoua B, Lingren A: Stroke in Qatar: a one-year, hospital-based study. J Stroke Cerebrovasc Dis 2001, 10(5):236-241.

30. El ZS, Ahmed M, Prakash PS, Hassan KM: Stroke: Incidence and pattern in Benghazi, Libya. Ann Saudi Med 1995, 15(4):367-369.

31. Al-Jishi A, Mohan P: Profile of stroke in Bahrain. Neurosciences 2000, 5:30-34.

32. Benamer HT, Grosset D: Stroke in Arab countries: A systematic literature review. J Neurol Sci 2009

33. Connor MD, Walker R, Modi G, Warlow CP: Burden of stroke in black populations in sub-Saharan Africa. Lancet Neurol 2007, 6(3):269-278.

34. Feigin VL, Lawes CM, Bennett DA, Anderson CS: Stroke epidemiology: a review of population-based studies of incidence, prevalence, and casefatality in the late 20th century. Lancet Neurol 2003, 2(1):43-53.

35. Sridharan SE, Unnikrishnan JP, Sukumaran S, Sylaja PN, Nayak SD, Sarma PS, Radhakrishnan K: Incidence, types, risk factors, and outcome of stroke in a developing country: the Trivandrum Stroke Registry. Stroke 2009, 40(4):1212-1218

36. Lavados PM, Hennis AJ, Fernandes JG, Medina MT, Legetic B, Hoppe A, Sacks C, Jadue L, Salinas R: Stroke epidemiology, prevention, and management strategies at a regional level: Latin America and the Caribbean. Lancet Neurol 2007, 6(4):362-372.

37. Liu M, Wu B, Wang WZ, Lee LM, Zhang SH, Kong LZ: Stroke in China: epidemiology, prevention, and management strategies. Lancet Neurol 2007, 6(5):456-464

38. UK Office for National Statistics: Census 2001. 2009 [http://www.statistics. gov.uk].

39. US Census Bureau - 2006. 2009 [http://www.census.gov/population/www/ index.html].

40. Sudlow CL, Warlow CP: Comparing stroke incidence worldwide: what makes studies comparable? Stroke 1996, 27(3):550-558.

41. Feigin V, Hoorn SV: How to study stroke incidence. Lancet 2004 363(9425):1920

42. Brainin $M$, Teuschl $Y$, Kalra L: Acute treatment and long-term management of stroke in developing countries. Lancet Neurol 2007, 6(6):553-561.

43. Esteghamati A, Abbasi M, Alikhani S, Gouya MM, Delavari A, Shishehbor MH, Forouzanfar M, Hodjatzadeh A, Ramezani RD: Prevalence, awareness, treatment, and risk factors associated with hypertension in the Iranian population: the national survey of risk factors for noncommunicable diseases of Iran. Am J Hypertens 2008, 21(6):620-626.

44. Bahrami H, Sadatsafavi M, Pourshams A, Kamangar F, Nouraei M, Semnani S, Brennan P, Boffetta P, Malekzadeh R: Obesity and hypertension in an Iranian cohort study; Iranian women experience higher rates of obesity and hypertension than American women. BMC Public Health 2006, 6:158.

45. Kamran S, Bener AB, Deleu D, Khoja W, Jumma M, Al Shubali A, Inshashi J, Sharouqi I, Al Khabouri J: The level of awareness of stroke risk factors and symptoms in the Gulf Cooperation Council countries: Gulf Cooperation Council stroke awareness study. Neuroepidemiology 2007, 29(3-4):235-242.

46. Mousavi SA, Hoseini T: Difference between risk factors of anterior and posterior circulation strokes. Journal of Research in Medical Sciences 2007 12(4):161-164

47. Subramanian G, Silva J, Silver FL, Fang J, Karpal MK, Oczkowski W, Gould L, O'Donnell MJ: Risk Factors for Posterior Compared to Anterior Ischemic Stroke: An Observational Study of the Registry of the Canadian Stroke Network. Neuroepidemiology 2009, 33(1):12-16. 
48. Khosravi A, Rao C, Naghavi M, Taylor R, Jafari N, Lopez AD: Impact of misclassification on measures of cardiovascular disease mortality in the Islamic Republic of Iran: a cross-sectional study. Bull World Health Organ 2008, 86(9):688-696.

49. Feigin VL: Stroke in developing countries: can the epidemic be stopped and outcomes improved? Lancet Neurol 2007, 6(2):94-97.

50. Feigin VL, Lawes CM, Bennett DA, Barker-Collo SL, Parag V: Worldwide stroke incidence and early case fatality reported in 56 population-based studies: a systematic review. Lancet Neurol 2009, 8(4):355-369.

51. Pakdaman H: Epidemiologic survey of CVA in the public hospoitals of Tehran in the years.1365-1369, [Iran: 1996].

52. Ashrafi H: The Report of 543 Cases of Stroke and Evaluation of the Early Sings of Stroke. Urmia Medical Journal 1996, 7(1\&2):47-53.

53. Janghorbani M, Hamzehee-Moghadam A, Kachoiee H: Epidemiology of Non-Fatal Stroke in South-Eastern Iran. Iranian Journal of Medical Sciences 1996, 21(3\&4)

54. Mahmoodi M, Islami MH: Epidemiological evaluation of 100 cases of stroke admitted to the Railway Hospital in Yazd. Iran: Shahid Sadooghi Medical School in Yazd 2004

55. Khandaghi R: Statistical study of the rate of intracranial hemorrhage comparing with other cerebrovascular diseases. Medical Journal of Tabriz University of Medical Sciences \& Health Services 1994, 28(22):16-21.

56. Azimian M, Zahed Z: Measurement of frequency of Ischemic stroke and risk factors in neurology ward of Sinal Hospital of Hamadan. The Journal of Hamadan University of Medical Sciences 2000, 7(2):1616.

57. Masoud S, Taghaddosi M: Evaluation of Short-term and Intermediate Prognosis in Stroke, Kashan (1996-1997). Research and Scientific Journal of Feidh 1999, 12:18-24

58. Ashrafi H, Sarsar Shahi A, Motamedian M, Allahyari M, Entezari A, Sina A Heshmat R: Intracranial Hemorrhage and Risk Factors Frequency in Motahary Hospital, Urmia. Urmia Medical Journal 2001, 3(12):254-260.

59. Miabi Z, Omrani M: Spontaneous Intracranial Haemorrhage: Results of Original CT Scans, Clinical Presentations and Risk Factors, Imam and Razi Hospitals, Tabriz. The Journal of Tehran University of Medical Sciences 2003, 61(1):17-23.

60. Ravari A, Mirzaee T, Esmaili A: Cerebrovascular Accident Risk Factors in Patients with Stroke in Neurology Ward of Ali Ibn Abitaleb Hospital, Rafsanjan. The Journal of Rafsanjan University of Medical Sciences 2002, 1(3):181-187

61. Noor Mohammadi S, Roodbari S, Golipoor FA: Survey of Cerebrovascular Accident in Young Adults. The Journal of Gilan University of Medical Sciences 1999, 8(29 \& 30):1-7

62. Harirchian MH, Ghaffarpour M, Doratotaj D, Akhavirad B: Stroke in young adults: A retrospective study of 68 cases. Acta Medica Iranica 2006, 44(2):119-124

63. Andelib P, Mahageri M, Nabipour I, Jafari S: Risk factors for stroke in Bushehr; a prospective study. Medicine in South (Tebbe Jonoob) 1999, 2(2):110-120.

64. Asadpour $\mathrm{H}$, Ibne Rasouli S: The study of incidence rate of stroke and its risk factors in Sanandaj in 1998. The Journal of Sanandaj University of Medical Sciences 2000, 4(15):41-44.

65. Masoud SA: Survey of the Prevalence of Stroke Risk Factors in CVA Diagnosed Patients, Hospitalized in Shahid Beheshti Hospital in 1998. Iranian Journal of Public Health 2002, 31(1-2):21-22.

66. Razaazian N, Homayoonfar H: Mortality of Stroke at Farabi Hospital (Kermanshah, 1998-2000). Behbood 2003, 6(4):38-46.

67. Hosseini SA, Bazrafshan HA: statistical study on the role of high-risk factors in the incidence of CVA. The Journal of Gorgan University of Medical Sciences 2001, 3(8):76-80

68. Emad Zadeh M, Etemadi M, Talebi S: Etiology of Ischemic Stroke in Young Adult Patients (15-45 years old) in Ghaem Hospital, Mashhad. The Journal of Mashhad University of Medical Sciences 2005, 48(87):57-62.

69. Sabet B, Derakhshan R, Sadeghi M, Sarrafzadegan N, Derakhshan F, Hosseini SH: Two-Year Incidence of Acute Fatal and Non-Fatal Coronary Events and Stroke: Iranian Population Over 35 Years Old. Advanced Research Yeilds Across Atherosclerosis (ARYA) Journal 2005, 1(1):9-14.

70. Ghandehari K, Izadi-Mood Z: Etiology of young adult onset brain infarction in Iran. Archives of Iranian Medicine 2006, 9(3):240-243.

71. Ahangar AA, Sanaat A, Saghebi R: Evaluation of Risk Factors in Stroke (Babol, 2001-2003). Journal of Babol University of Medical Sciences 2005, 7(3):55-60.
72. Ghandehari K, Izadi-Mood Z: Khorasan stroke registry: analysis of 1392 stroke patients. Archives of Iranian Medicine 2007, 10(3):327-334.

73. Savadi Oskoui D, Aminisani N, Hashemilar M: Major Risk Factors of Ischemic Stroke in Women, 2002. Journal of Ardabil University of Medical Sciences 2003, 2(7):23-27.

74. Savadi Oskoui D, Aminisani N, Hashemilar M: The Relationship between Taking Oral Contraceptive Pills and the Risk of Ischemic Stroke. Journal of Ardabil University of Medical Sciences 2003, 2(8):45-50

75. Noubahar M, Vafayee AA, Samayee A, Masoomi S: Risk factors of stroke in men and women. Chapter of Neurosciences Journal 2006, 5(13):19-25.

76. Dodangeh A, Mahdavi Z, Kamrani F, Alavi Majd H, Abed Saeidi J: Comparing Risk Factors in Ischemic and Hemorrhagic Strokes. Iran: Shahid Beheshti University of Medical Sciences, Tehran 2003.

77. Tavassoli A, Ghofrani M: Evaluation of Epidemiology and Aetiology of Cerebrovascular Diseases in Children. Journal of Iranian Pediatric Diseases 2009, 18(1):53-58.

78. Aminisani N, Savadi Oskoui D, Shamshirgeran SM, Dastgiri S, Hashemilar M, Jafaryani M: One-month mortality of stroke in the province of Ardabil, 1383. The Journal of Ardabil University of Medical Sciences 2007, 7(4):353-356.

79. Hashemilar M, Savadi Oskoui D, Jafaryani M, Aminisani N: An Etiologic Study of Cerebrovascular Ischemic Events in Young Adults Reffering to Alavi Hospital in Ardabil, 2004 - 2005. The Journal of Ardabil University of Medical Sciences 2006, 1:78-83.

80. Iranmanesh F, Farahmand $\mathrm{H}$ : Large Vessel Atherosclerotic Infarction and Lacunar Lesions. Acta Neurol Taiwanica 2007, 16:203-206.

81. Iranmanesh F, Pour Gholami M, Sayyadi A: Silent Stroke in Patients with Acute Thrombotic Stroke. Hormozgan Medical Journal 2006, 10(3):237-241.

\section{Pre-publication history}

The pre-publication history for this paper can be accessed here: http://www.biomedcentral.com/1471-2377/10/72/prepub

doi:10.1186/1471-2377-10-72

Cite this article as: Hosseini et al:: Frequency and clinical patterns of stroke in Iran - Systematic and critical review. BMC Neurology 2010 10:72.

\section{Submit your next manuscript to BioMed Central and take full advantage of:}

- Convenient online submission

- Thorough peer review

- No space constraints or color figure charges

- Immediate publication on acceptance

- Inclusion in PubMed, CAS, Scopus and Google Scholar

- Research which is freely available for redistribution
Biomed Centra 